\title{
CITATION ANALYSIS FOR COLLECTION DEVELOPMENT: A COMPARATIVE STUDY OF EIGHT HUMANITIES FIELDS ${ }^{1}$
}

\author{
Jennifer E. Knievel ${ }^{2}$ and Charlene Kellsey ${ }^{3}$
}

This study analyzes 9,131 citations from the 2002 volumes of journals in eight humanities fields: art, classics, history, linguistics, literature, music, philosophy, and religion. This study found that citation patterns varied widely among humanities disciplines. Due to these differences, it is important for librarians with humanities collection development responsibilities to consider each field separately when making collection development decisions. The authors investigated the language of sources cited in each field. Foreign language citations continue to be dominated by French and German. This study also confirms that, in most humanities disciplines, monographs remain the dominant format of cited sources, although some fields cited monographs less frequently than expected.

\section{Introduction}

Collection development in research libraries is, at best, an inexact science or, more properly, an art. With ever-increasing amounts of materials available and perennial budget constraints, it is important to use as much concrete information as possible when making purchasing decisions. Many studies of the sciences confirm the overwhelming predominance of journal articles and the use of English in citations by science scholars [1]. In fact, according to Eugene Garfield, founder of Science Citation Index, 95 percent of the 925,000 science articles published in 1997 were written in English [2]. The picture in the humanities is less clear and more varied

1. The authors would like to thank Keith Gresham, M. Winslow Lundy, and Patricia Morris for their substantive comments on this article.

2. Assistant professor, humanities reference and instruction librarian, and bibliographer for philosophy and linguistics at the University of Colorado at Boulder, University Libraries, 184 UCB, Boulder, CO 80309; Telephone 303-492-8887; E-mail jennifer.knievel@colorado.edu.

3. Associate professor, monographic cataloger, and bibliographer for classics at the University of Colorado at Boulder, University Libraries, 184 UCB, Boulder, CO 80309; Telephone 303-492-1183; E-mail charlene.kellsey@colorado.edu.

[Library Quarterly, vol. 75, no. 2, pp. 142-168]

(C) 2005 by The University of Chicago. All rights reserved. 0024-2519/2005/7502-0003\$10.00 
among fields. Although a number of citation analysis studies look at the humanities as a whole, existing studies of individual fields show considerable variation (see literature review below). Most of the studies report on the use of books versus journals, but only a few report on the languages of the cited works. The methods used in the available studies vary, and the definition of what is included in each of the categories reported also varies, making comparisons of the humanities fields difficult.

The purpose of the present study is to provide a comparison of citation practices in eight humanities fields, using a consistent method and reporting on the same year for all eight. The fields chosen for this study were art, classics, history, linguistics, literature, music, philosophy, and religion. Two major characteristics were investigated: the use of foreign language resources by the scholars in each field and the relative percentages of books and journals cited. It is hoped that this information will assist bibliographers and collection development librarians in the daily decisions they have to make. For example, if it is found that a particular field uses very few foreign language resources, it may be possible to discontinue purchasing those sources. Alternatively, if it is found that another field uses a higher proportion of journals than previously assumed, this may affect cancellation or off-site storage decisions.

\section{Literature Review}

There are a number of articles that summarize previous citation studies in the humanities, including those by Rebecca Watson-Boone, Michael Bowman, Robin Devin, and Martha Kellogg [3-5]. They all report on the books versus serials issue, but because they are reporting results from a large number of studies that used a variety of data collection methods, the percentages found for each field are not necessarily comparable. Few studies report on foreign language books and journals cited in humanities fields. A large study of foreign language use by humanities scholars at a British university in the 1960 s used a variety of methods to gather data, including a citation analysis of books and theses produced by the scholars at that university [6]. They found that 72.3 percent of citations were to English sources, 11.4 percent to German, and 5.35 percent to French, with Spanish and Italian less than 1 percent, and 9.8 percent to other languages $(n=1,731)$ [6, p. 106]. The fields included in that study were applied linguistics, biblical studies, English language and literature, ancient and modern history, classics, music, and philosophy. Their selection of fields is similar, with the exception of the additional field of art history in this study.

Further references to the citation analysis literature may be found in 
the extensive annotated bibliography of Jean-Pierre Herubel and Anne Buchanan, as well as in the more recent study by Jennifer Thompson, the results of which will be discussed below $[4,7,8]$. Citation studies of individual fields will be discussed in the "Results and Discussion" section of this article in order to facilitate comparison with the data for each field. This study is one of very few that analyzes several different humanities fields with the same method. The age of many of the previous studies also indicated the necessity of a new study to assess current practices of humanities scholars.

\section{Method}

The authors counted 9,131 citations in the 2002 volumes of one journal in each of eight humanities fields: art, classics, history, linguistics, literature, music, philosophy, and religion. Previous research has shown that humanities fields have widely varying citation patterns [9]. These eight fields were chosen to represent a diverse range of humanist approaches to research. Though monographs are more heavily used than journals in the humanities, there is no consistent way to choose comparable monographs in each discipline. The authors decided, therefore, to count citations from one major journal in each field. Since this study is looking particularly at the citation habits of scholars in the United States, only journals with a U.S. imprint were included. The authors also looked for journals that did not focus on a subfield in any one discipline but rather approached the subject broadly. This study builds upon data the authors collected for an earlier study [9]. The previous study analyzed citations in the fields of philosophy, history, linguistics, and classics over a period of forty years. The current study uses the data for those four fields collected for the year 2002 and adds data collected for the same year in the fields of art, music, religion, and literature.

Journals Selected for Analysis

The authors sought an art journal that focused on the objective study of art, rather than art criticism. Alexandra De Luise describes Art Bulletin as the "principal journal for scholarly art historical research in the world . . . [with] highly specialized articles on all periods and areas of art history" [10, p. 82]. In classics, the authors chose the American Journal of Philology. Classical Studies: A Guide to the Reference Literature describes the American Journal of Philology as "one of the oldest and best classical journals published in America" [11, p. 186]. It was the best choice of U.S. imprint journals that was broad both in its treatment of the subject and in its target audience.

The most appropriate journal in history was the American Historical Re- 
view. This is the journal chosen to represent history in various other citation analysis studies [12, 13]. It is also the indisputable leader in impact, according to the Journal Citation Reports (JCR) impact factor analysis, among history journals with broad subject coverage and a U.S. imprint. Unfortunately, no other subjects investigated for this study are included in JCR, and no comparable analysis is available from the Arts and $\mathrm{Hu}$ manities Citation Index. In linguistics, the authors chose the journal Language. Linguistics: A Guide to the Reference Literature describes Language as "a major scholarly, general linguistics journal" [14, p. 116]. A. J. Nederhof and R. A. Zwaan's extensive survey indicates a list of core linguistics journals [15]. Language was the best selection from that list that met our selection criteria for this study.

In selecting a journal in the field of literature, the authors chose to study a general literature journal because literature fields in specific languages (e.g., French literature, English literature) would hold a determined language bias in the cited sources. The Proceedings of the Modern Languages Association (PMLA) varied most in its inclusion of articles, and PMLA is indisputably the most dominant journal in the broad field of the literatures of many languages, especially when measured by circulation. The subdisciplines in the field of music are less similar to other humanities fields and include applied areas such as performance and music education. Musicology was more appropriate because it includes the more humanistic aspect of research comparable to the other humanities fields included in this study. Many of the major musicology journals carry a European imprint; options with U.S. imprints were fewer. Alan Karass describes the Journal of the American Musicological Society (JAMS) as "the foremost American musicological journal" [16, p. 105]. In addition, Lois Kuyper-Rushing's study of core journals in music shows that JAMS is, by a wide margin, the most frequently cited journal in musicology dissertations nationwide. William S. Brockman describes articles in JAMS as "solid and scholarly, yet written for a wide audience" [17, p. 173].

In philosophy, the authors chose the Journal of Philosophy. According to Philosophy: A Guide to the Reference Literature, the Journal of Philosophy is "one of the most widely circulated philosophical journals . . . varying considerably in content" [18, p. 184]. Further support of this choice is John Cullars's description: the Journal of Philosophy is the only U.S.-imprint, general philosophy journal that covers "virtually all areas of philosophy" [19, p. 51]. The authors sought a journal of religion that represented a broad focus on religion, rather than only a Judeo-Christian or denominationspecific perspective, and one that took an objective approach to the study of religion. Donna L. Gilton includes the Journal of Religion in a short list of "academic journals covering all religions generally" [20, p. 28]. Eugene C. Fieg Jr. describes the Journal of Religion as a journal "aimed at the scholar 
who studies religion from a purely objective, phenomenological point of view" [21, p. 13]. James Dawsey describes it as a journal that seeks "articles which display a high quality of scholarship and have significance for a wide readership in religious studies" [22, p. 19].

\section{Citation Counting Criteria}

The authors made a determined effort to duplicate the criteria for citation counting used in an earlier study in order to be able to combine and compare data from that study with data added for the current study [9]. Categories of included citations were books and journals in English, German, French, Italian, Spanish, Portuguese, and Latin. All other language materials were grouped into "other language books" and "other language articles." Book chapters and dissertations were counted as books. Translations were counted as books or articles in the language into which they were translated since the authors' interest was in the language of materials researchers are using. Many researchers cited sources both as journal articles and as reprinted book chapters. In these cases, the authors made every effort to determine which version the researcher used as a source and counted that version for the purposes of our citation analysis. Citations excluded from this citation analysis were newspapers, reviews, unpublished manuscripts, presentations, and source documents that the article was evaluating. Source documents would include, for example, a work by Cicero that was the subject of an article in classics. Articles that were responses to previous articles or conference previews were not analyzed.

Many complications arose during counting. Unlike most journal articles in the sciences, articles in the humanities often include their citations only in discursive footnotes or within the text itself, making citation counting more difficult. In cases of incomplete or in-text-only citations, the authors made every effort to determine the language of the source based upon the available information. A total of 9,131 citations were included for analysis in this study and were manually counted and entered into spreadsheets, which were used to calculate totals and percentages of all data.

Results and Discussion

The most consistent result of this study is the variation among the citation patterns of the various humanities fields. Overall, scholars in all eight fields cited an average of 78.2 percent English-language materials. However, the individual fields varied from as little as 65.3 percent English-language sources (art) to 99.7 percent English-language sources (philosophy). In all eight fields combined, French was the most common language cited (5.3 percent of all citations), followed by German ( 4.7 percent) and Italian 


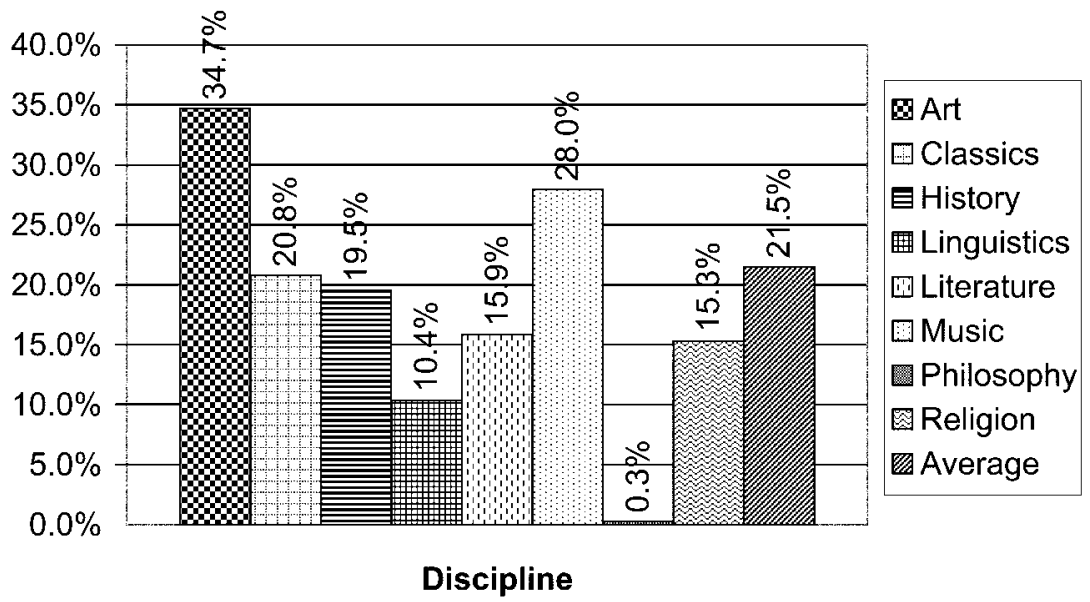

Fig. 1.-Citations to foreign language sources. Total number of citations counted was 9,131. Percentages are of total citations counted in all languages and source types for each discipline and are rounded to the nearest tenth.

(4.4 percent). This pattern does not hold true in each of the various fields, however. The most common foreign language was German in classics, linguistics, and religion; French in history, literature, and music; and Italian in art. All fields showed little use of Spanish and Portuguese language materials. No single foreign language is dominant in all humanities fields, which underscores the importance of not making humanities collection development decisions based on averages of different humanities fields. Figures 1 and 2 show percentages of foreign language citations in each field.

In all eight fields combined, books represent 74.3 percent of all citations, a number that is fairly consistent with other citation studies of the humanities [4]. Figure 3 shows, however, that the percentage of citations to monographs in this study varied by discipline from 51.4 percent (philosophy) to 88.2 percent (religion)

The combined humanities fields had an average of 62.5 citations per article (see tables 1 and 2) compared with an average of 40.4 citations per article found in a study of biology by Claudia Lascar and Loren Medelsohn [1]. This again varied by field from a low of 28.4 citations per article in philosophy to a high of 112.7 citations per article in art. The authors counted a scant 31 citations, or 0.3 percent, to Internet-only sources in the 2002 volumes, indicating a near absence of Internet-only sources in the humanities so far. This stands in stark contrast to the results of a study by Susan Herring. Herring studied an interdisciplinary selection of articles. More than half of all articles in her study cited at least one electronic 


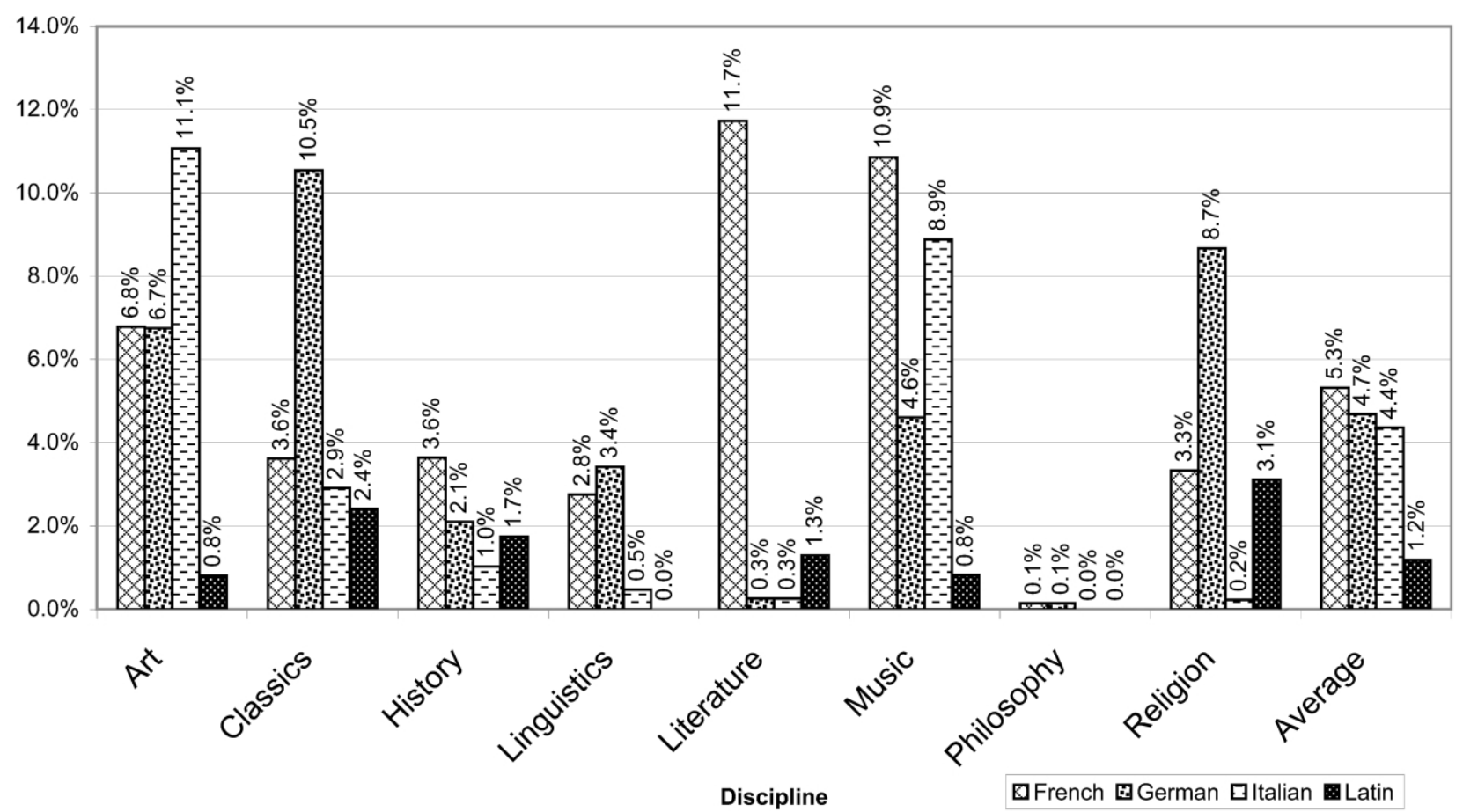

FIG. 2.-Distribution of foreign language citations. Total number of citations counted was 9,131. Languages counted but not displayed were Spanish, Portuguese, and "other." All were too small to be usefully displayed. 


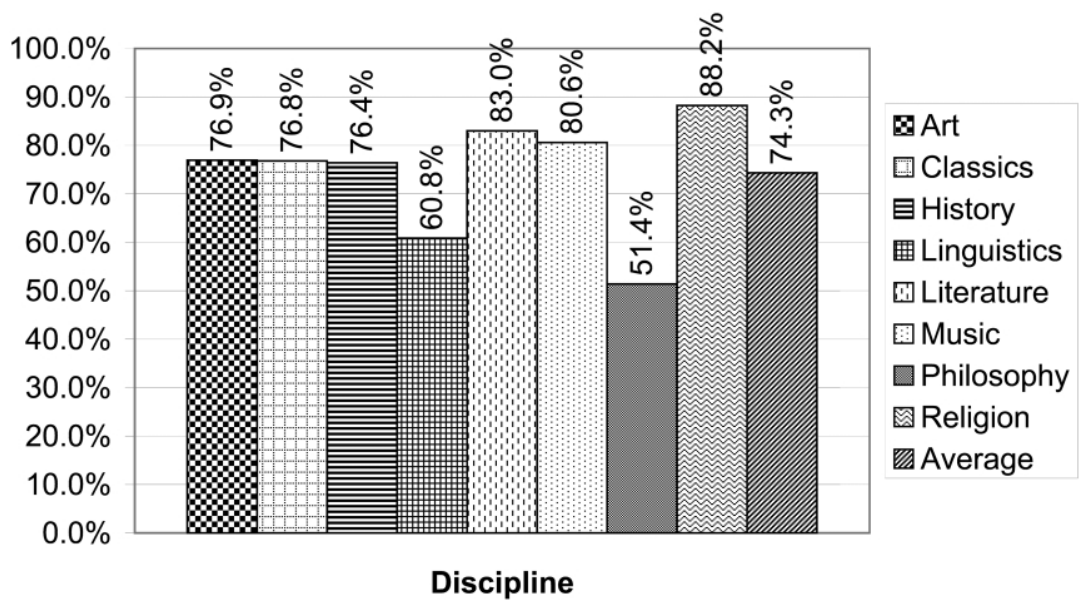

FIG. 3.-Citations to monographs. Total number of citations counted was 9,131. Percentages are of total citations counted in all languages and source types for each discipline and are rounded to the nearest tenth.

source, and citations to online sources accounted for 16 percent of all citations [23]. The only humanities field studied by Herring (religion) cited only one electronic source, which is consistent with the low usage of electronic sources identified by the current study.

Given the wide disparities among humanities disciplines, the overall averages of all fields are rarely generalizeable to individual humanities fields. Therefore, the results of this study are presented by subject.

Art

The most recent citation analysis in art history is a case study by Barkett of citations found in five years (1994-98) of Art Bulletin [24]. Her method differed from that of the current study in that she counted citations from the lists of works most frequently cited at the end of each article, whereas this study counted citations from all of the endnotes. She also broke down the format of the citations into many categories; however, since she provided the raw numbers, in addition to the percentages, it was possible to recalculate the percentages for combinations of formats that approximate those of the current study. These recalculated percentages were 84.0 percent to monographs and 15.3 percent to journals. Barkett also looked at the language of the cited works and found that 58.2 percent were English, 13.7 percent Italian, 12.9 percent French, 3.7 percent Chinese, 3.6 percent 
TABLE 1

All Fields: Statistics

\begin{tabular}{|c|c|c|c|}
\hline Statistic & $\begin{array}{l}\text { Total, All } \\
\text { Fields }\end{array}$ & $\begin{array}{l}\text { Average per } \\
\text { Field }\end{array}$ & Percentage \\
\hline Total citations & $9,131.0$ & $1,141.4$ & . . . \\
\hline Total pages 2002 volumes & $3,526.0$ & 440.8 & . . . \\
\hline Total articles 2002 volumes & 146.0 & 18.3 & . . . \\
\hline Average pages per article & $\ldots$ & 24.2 & . . . \\
\hline Average citations per article & . . . & 62.5 & . . \\
\hline Average citations per page & . . & 2.6 & . . \\
\hline Total monographs cited & $6,787.0$ & 848.4 & 74.3 \\
\hline Total articles cited & $2,313.0$ & 289.1 & 25.3 \\
\hline Electronic sources & 31.0 & 3.9 & .3 \\
\hline Citations to English monographs & $5,188.0$ & 648.5 & 56.8 \\
\hline Citations to English articles & $1,951.0$ & 243.9 & 21.4 \\
\hline Citations to foreign language monographs & $1,599.0$ & 199.9 & 17.5 \\
\hline Citations to foreign language articles & 362.0 & 45.3 & 4.0 \\
\hline
\end{tabular}

German, 2.5 percent Japanese, 2.5 percent Spanish, and a few other languages with smaller percentages.

Another relevant study is Cullars's 1992 study of a random sample of citations from fine arts monographs $(n=581)$ in which he found 60.6 percent were to monographs, 23.6 percent to journals, 14.8 percent to manuscripts, and 1 percent to theses [25]. He also looked at the language of the cited works and found that 70.2 percent were in English, 11.9 percent in French, 5.5 percent in German, 5.2 percent in Italian, 1.7 percent in Latin, 3.1 percent in Spanish, and 2.4 percent in other languages. Interestingly, he notes that Simonton found German to be used more than French in his study in the 1950s, indicating a shift in languages used over the thirty years separating their studies [26]. Cullars's related 1996 study looks at French and German fine arts monographs and provides an in-

TABLE 2

All Fields: Language Distribution

\begin{tabular}{lrc}
\hline \hline Language Distribution & Number & Percentage \\
\hline English & 7,139 & 78.2 \\
German & 427 & 4.7 \\
French & 485 & 5.3 \\
Italian & 398 & 4.4 \\
Spanish & 81 & .9 \\
Portuguese & 2 & 0 \\
Latin & 108 & 1.2 \\
Other languages & 460 & 5.0 \\
All foreign languages & 1,961 & 21.5 \\
\hline
\end{tabular}


TABLE 3

Art: STATistics

\begin{tabular}{lrc}
\hline \hline Statistic & Number & Percentage \\
\hline Total citations & $2,593.0$ & $\ldots \ldots$ \\
Total pages 2002 volumes & 475.0 & $\ldots$ \\
Total articles 2002 volumes & 23.0 & $\ldots$ \\
Average pages per article & 20.7 & $\ldots$ \\
Average citations per article & 112.7 & $\ldots$ \\
Average citations per page & 5.5 & $\ldots$ \\
Total monographs cited & $1,995.0$ & 76.9 \\
Total articles cited & 597.0 & 23.0 \\
Electronic sources & 1.0 & 0 \\
Citations to English monographs & $1,234.0$ & 47.6 \\
Citations to English articles & 458.0 & 17.7 \\
Citations to foreign language monographs & 761.0 & 29.3 \\
Citations to foreign language articles & 139.0 & 5.4 \\
\hline
\end{tabular}

teresting comparison to the citation practice of English-speaking scholars [27].

A study by Erika Dowell compares subject area of citations in Art Bulletin and Burlington Magazine in order to demonstrate the interdisciplinarity of the field but includes no statistics on language or on the number of citations in books and in journals [28]. The article by Diane Nelson includes a good discussion of the use of citation analysis in art, but her study was of catalogs of Chinese bronzes, a specialized field [29]. Both of these studies, however, also note the dissertation of Wesley Clark Simonton, who found only a 28 percent use of serials (including annuals and museum bulletins) in the fine arts from 1948 to 1957 (see tables 3 and 4).

Of all subjects selected for this study, art deviated most from the humanities average. Art had the highest number of citations by a large margin,

TABLE 4

Art: Language Distribution

\begin{tabular}{lrc}
\hline \hline Language Distribution & Number & Percentage \\
\hline English & 1,692 & 65.3 \\
German & 175 & 6.7 \\
French & 176 & 6.8 \\
Italian & 287 & 11.1 \\
Spanish & 7 & .3 \\
Portuguese & 1 & 0 \\
Latin & 21 & .8 \\
Other languages & 233 & 9.0 \\
All foreign languages & 900 & 34.7 \\
\hline
\end{tabular}


with 2,593 in one volume. Art had 636 more citations than history, the next highest, and had more than double the average number of citations per field $(1,141.4)$. While art had more articles than some other subjects did (23 compared with the average of 18.3), it did not have the most articles in one volume. The average length of articles in art, 20.7 pages, was less than the average article length (24.2 pages), although the page size of Art Bulletin is larger than that of most humanities journals. It follows, then, that art also had the highest citations per article at 112.7 and the highest citations per page at 5.5. Art proved to be an outlier in a number of other areas as well. An unusually high 6.7 percent of citations were to German materials, and an extraordinary 11.1 percent of citations were to Italian materials. The number of citations to each foreign language in art was higher than average, measured both in percentages and in actual numbers, in every language except Spanish and Latin. Art was also the least English-dominated field of all eight fields studied, with only 65.3 percent of citations referring to English materials. Although the authors did not track exact numbers of Chinese, Japanese, and Korean (CJK) citations, art scholars also cited high numbers of CJK sources. These comprised the bulk of the other languages category in art, reflecting the inclusion of articles on Asian art in most issues of Art Bulletin. The percentages of citations referring to monographs, both in English and in foreign languages, were only slightly above average.

Some of the results of this study were different than the results obtained in the Barkett and, especially, the Cullars study [24, 25]. The current study found 76.9 percent of citations were to monographs; this is substantially higher than the 60.6 percent in Cullars's study but lower than the 84 percent found by Barkett. This discrepancy may be due to several factors. Cullars counted citations from monographs rather than from journals, as in this study. He also counted 14.8 percent manuscripts, which were excluded from the present study, which would affect the percentages that books and journals had of the total citations he counted. Barkett counted citations from the works most frequently cited lists, and it is likely that monographs would be included in those lists more often since they have much more material to discuss and cite than a journal article, which may only be mentioned once in the notes.

This study found 65.3 percent of citations were to English-language materials, noticeably lower than Cullars's 70.6 percent, but higher than Barkett's 52.5 percent. Cullars also found a two-times-higher percentage of citations to French than to German or Italian, which suggests a shift from earlier practices noted in the 1959 study by Simonton. The current study found almost an equal amount of citations to French and German sources, calling into question such a language shift in the field. This study also found a much higher percentage of citations to Italian. Barkett also found 
a high percentage of citations to Italian, with French a close second and German much further down. The variation in the relative percentages of each language reported in the different studies may simply reflect the topics covered in the articles or books selected for study and, thus, should be treated with caution. For example, quite a few of the articles in the 2002 volume of Art Bulletin treated topics in the Italian Renaissance, which likely contributed to the high percentage of Italian citations reported in this study. The relatively high proportion of foreign language to English citations, however, seems to be a reliable characteristic of the field of art history.

\section{Classics}

The only study of classics found was fairly old and, thus, may not reflect current practice in the field. In his MS thesis on citations in the classics annual, Transactions of the American Philological Association, Benny Ray Tucker found 54.8 percent of citations to books; 16.4 percent to annuals, encyclopedias, Festschriften, and dissertations (a total of 71.2 percent); and 28.5 percent to journals [30]. Citations to English-language sources represented only 45.5 percent of the total citations; German was the most cited foreign language at 31.1 percent, followed by French at 11.3 percent, Italian at 7.7 percent, and Latin at 3.3 percent (see tables 5 and 6).

In a previous study, which used some of the same data, classics appeared to be an outlier among humanities fields in its use of foreign languages [9]. The inclusion of other humanities fields in the current study demonstrates that citation patterns in classics are much closer to the average than they appeared when compared only with history, linguistics, and philosophy. Classics scholars cited 79.2 percent English-language materials, very close to the overall average of 78.2 percent. Although Tucker found a considerably lower percentage of English language sources (45.5 percent) in the 1956 and 1957 volumes of a different journal, the authors also found, in an earlier study, a low percentage (54.6 percent) in the 1962 volume of American Journal of Philology [9]. As reported in that longitudinal study, the percentage of English citations in classics did increase from 1962 to 2002, not because the raw numbers of foreign citations had declined, but because the numbers of English citations had increased considerably. Tucker reported only percentages, so, it is impossible to tell whether his raw numbers were comparable to those found for 1962. This illustrates the importance of reporting raw numbers as well as percentages in order to avoid drawing inappropriate conclusions from the data.

Classics, with 76.8 percent of citations referring to monographs, was very close to the overall average of 74.3 percent, although it was a little higher 
TABLE 5

Classics: Statistics

\begin{tabular}{lcc}
\hline \hline Statistic & Number & Percentage \\
\hline Total citations & 996.0 & $\ldots$. \\
Total pages 2002 volumes & 516.0 & $\ldots$ \\
Total articles 2002 volumes & 25.0 &. \\
Average pages per article & 20.6 &. \\
Average citations per article & 39.8 &. \\
Average citations per page & 1.9 &. \\
Total monographs cited & 765.0 & 76.8 \\
Total articles cited & 231.0 & 23.2 \\
Electronic sources & 0 & 0 \\
Citations to English monographs & 612.0 & 61.4 \\
Citations to English articles & 177.0 & 17.8 \\
Citations to foreign language monographs & 153.0 & 15.4 \\
Citations to foreign language articles & 54.0 & 5.4 \\
\hline
\end{tabular}

than the 71.2 percent found by Tucker. The average of 39.8 citations per article in classics was below the overall average of 62.5 citations per article. Citations to foreign language monographs (15.4 percent) were lower than average in classics, while citations to foreign language articles were higher (5.4 percent), indicating that foreign language sources in classics were less dominated by monographs than in other fields. This study found German to be the most cited foreign language in classics by a proportion of almost three to one over French, followed by Italian, which is similar to the proportions found by Tucker [30].

TABLE 6

Classics: Language Distribution

\begin{tabular}{lcc}
\hline \hline Language Distribution & Number & Percentage \\
\hline English & 789 & 79.2 \\
German & 105 & 10.5 \\
French & 36 & 3.6 \\
Italian & 29 & 2.9 \\
Spanish & 1 & .1 \\
Portuguese & 0 & 0 \\
Latin & 24 & 2.4 \\
Other languages & 12 & 1.2 \\
All foreign languages & 207 & 20.8 \\
\hline
\end{tabular}


History

In the field of history, the only study reporting statistics on format and language use is that of Clyve Jones, Michael Chapman, and Pamela Carr Woods [31]. They examined citations from seven journals in English history, which included about three different time periods (medieval, early modern, and later modern). They found 59.8 percent of citations were to published, nonserial items (including primary sources); 27.1 percent were to serials; and 12.6 percent were to unpublished material, manuscripts, and theses. Again, because the present study excluded primary sources and unpublished material, and the Jones, Chapman, and Woods study did not report raw numbers, one cannot compare the data from the two studies. Foreign citations in their study made up only 7.7 percent of all citations, with 3.3 percent to Latin, 2.5 percent to French, 1.2 percent to German, and 0.7 percent to other languages. This is understandable, considering the subject area was English history, but it is interesting to note that in the medieval field, 28.4 percent of the citations were to foreign sources, with 18.8 percent to Latin and 7.6 percent to French (other languages not reported). Other studies in history include one by Herubel, who examined three history journals. Herubel reports the number of foreign citations per journal but not percentages [32]. Herubel and Goedeken report only on the period and subject breakdown of the citations they examined [13]. M. Sara Lowe's study reports foreign language percentages; however, only one issue of volumes, twenty years apart, was examined. The small size of her sample might explain the wide variation of her results [12] (see tables 7 and 8).

History, like art and literature, had a very high average of citations per page and citations per article, making it one of the densest fields for citations. History also had a very high number of total citations with 1,957 (well above average), which was eclipsed only by art. Like classics and art, it is unusual in that the citations to foreign language articles (4.9 percent) were higher than average. Citations to English-language sources (80.5 percent) were also higher than average.

The current study found that 19.5 percent of citations in history were to foreign language sources, although it should be noted that, because there was an average of 103 citations per article, there was an average of 20.1 foreign citations per article. It is also interesting to note that the highest percentage foreign language was "other" at 9.1 percent, which would seem to indicate a wider variety of languages used by historians. In counting the citations, it was apparent that the languages used were very much related to the topic treated in the article and the geographic area in which it occurred. Thus, the research specialties of faculty at a particular 
TABLE 7

History: Statistics

\begin{tabular}{lrr}
\hline \hline Statistic & Number & Percentage \\
\hline Total citations & $1,951.0$ & $\ldots$ \\
Total pages 2002 volumes & 503.0 & $\ldots$ \\
Total articles 2002 volumes & 19.0 & $\ldots$ \\
Average pages per article & 26.5 & $\ldots$ \\
Average citations per article & 102.7 & $\ldots$ \\
Average citations per page & 3.9 &. \\
Total monographs cited & $1,495.0$ &. \\
Total articles cited & 456.0 & 76.4 \\
Electronic sources & 6.0 & 23.3 \\
Citations to English monographs & $1,209.0$ & .3 \\
Citations to English articles & 361.0 & 18.5 \\
Citations to foreign language monographs & 286.0 & 14.7 \\
Citations to foreign language articles & 95.0 & 4.9 \\
\hline
\end{tabular}

university should probably have a greater influence on collection development decisions regarding foreign language in history.

\section{Linguistics}

Bowman cites a British study of citations in monographs from 1971 that included linguistics and found 79.8 percent to books and 15.5 percent to journals, with 4.8 percent in other categories [4]. That study had a small sample size, however, so it is difficult to know how representative these percentages are (see tables 9 and 10).

In this study, linguistics demonstrated a much lower dominance of mono-

TABLE 8

History: Language Distribution

\begin{tabular}{lrc}
\hline \hline Language Distribution & Number & Percentage \\
\hline English & 1,570 & 80.5 \\
German & 41 & 2.1 \\
French & 71 & 3.6 \\
Italian & 20 & 1.0 \\
Spanish & 37 & 1.9 \\
Portuguese & 1 & .1 \\
Latin & 34 & 1.7 \\
Other languages & 177 & 9.1 \\
All foreign languages & 381 & 19.5 \\
\hline
\end{tabular}


TABLE 9

LiNGUisTics: STATISTICS

\begin{tabular}{lrc}
\hline \hline Statistic & Number & Percentage \\
\hline Total citations & $1,070.0$ & $\ldots$ \\
Total pages 2002 volumes & 524.0 & $\ldots$ \\
Total articles 2002 volumes & 16.0 & $\ldots$ \\
Average pages per article & 32.8 & $\ldots$ \\
Average citations per article & 66.9 & $\ldots$ \\
Average citations per page & 2.0 & $\ldots$ \\
Total monographs cited & 651.0 & 60.8 \\
Total articles cited & 402.0 & 37.6 \\
Electronic sources & 17.0 & 1.6 \\
Citations to English monographs & 575.0 & 54.6 \\
Citations to English articles & 369.0 & 35.0 \\
Citations to foreign language monographs & 76.0 & 7.2 \\
Citations to foreign language articles & 33.0 & 3.1 \\
\hline
\end{tabular}

graphs (60.8 percent) than any other field except philosophy. Also, as in philosophy, linguistics was strongly dominated by English-language sources with 89.6 percent of citations referring to sources in English. This was substantially higher than the overall average of 78.2 percent and particularly unexpected for a field that specializes in the study of language. The number of citations in linguistics $(1,070)$ was near average, as were the citations per article and citations per page. Of the foreign language citations that were used, German had a slightly higher number than French but, as with history, other languages had the highest number. Linguistics was also unusual in its citations to electronic sources. Although electronic sources represented only 1.6 percent of citations in the field, this was nevertheless the highest of any field studied.

TABLE 10

Linguistics: LANGUAge Distribution

\begin{tabular}{lrc}
\hline \hline Language Distribution & Number & Percentage \\
\hline English & 944 & 89.6 \\
German & 36 & 3.4 \\
French & 29 & 2.8 \\
Italian & 5 & .5 \\
Spanish & 1 & .1 \\
Portuguese & 0 & 0 \\
Latin & 0 & 0 \\
Other languages & 38 & 3.6 \\
All foreign languages & 109 & 10.4 \\
\hline
\end{tabular}


Literature

The largest numbers of citation studies are found in the field of literature. Cullars's study looked at citations from 30 monographs by native Englishspeaking scholars of foreign literature [33]. He found 81 percent of the total references $(n=18,481)$ were to books, 10.9 percent to articles, and the remainder were to manuscripts and theses; percentages for foreign citations only were slightly higher for both books and articles but were lower for manuscripts. For individual languages, 20 percent of the total citations were to French sources, 15 percent to Russian, 10 percent to German, 8 percent to Italian, 3 percent to Latin, and 1 percent each to Greek and Spanish, with "other" having 5 percent. These relatively high percentages for foreign citations are understandable in light of the subject being investigated by these scholars; only 37 percent of citations were to English sources. John Budd's study of American literature looked at citations from books, book articles, journal articles, and dissertations, principally to try to identify core books and journals, but he also reports numbers and percentages of types of materials [34]. He found that 64 percent of citations were to books, 26.7 percent were to serials (periodicals and newspapers), and the remainder were to manuscripts, unpublished letters, and dissertations. No analysis of language is included. Madeline Stern's study focuses on three literary authors and three movements of literary theory, reporting on format, primary versus secondary sources, and age distribution [35]. She found a range of 80.2 to 89.9 percent of citations were to books for the literary authors and 75.1 to 83.3 percent for the literary theory. Thompson examined citations in studies of nineteenthcentury British and American literature from both books and journals [8]. She broke out primary and secondary sources cited; among the secondary sources (of most relevance to the present study), she found that 66.9 percent were to books, 14.2 percent were to book articles (total $=81.1$ percent), and 18.0 percent were to journals, with remaining miscellaneous categories having less than 1 percent each $(n=3,938$ for secondary sources; see tables 11 and 12).

In this study, the shortest articles were in literature. This is undoubtedly the effect, however, of a strict word limit in PMLA. With 776 citations for the entire volume, the number of citations in literature was below average (average was 1,141.4). However, literature had a very high average of citations per page (3.2), identifying literature as a field with a high density of citations. It is likely, therefore, that the number of citations was an effect of the short articles in PMLA and that, in the cases of longer articles, literature is likely to be a field with high numbers of citations. Surprisingly, citations in literature included almost no German language sources in either books or journals. In contrast, literature scholars cited 11.7 percent 
TABLE 11

Literature: STATISTICS

\begin{tabular}{lcc}
\hline \hline Statistic & Number & Percentage \\
\hline Total citations & 776.0 & $\ldots$. \\
Total pages 2002 volumes & 243.0 & $\ldots$ \\
Total articles 2002 volumes & 16.0 & $\ldots$ \\
Average pages per article & 15.2 & $\ldots$ \\
Average citations per article & 48.5 & $\ldots$ \\
Average citations per page & 3.2 & $\ldots$ \\
Total monographs cited & 644.0 & 83.0 \\
Total articles cited & 129.0 & 16.6 \\
Electronic sources & 3.0 & .4 \\
Citations to English monographs & 535.0 & 68.9 \\
Citations to English articles & 115.0 & 14.8 \\
Citations to foreign language monographs & 109.0 & 14.0 \\
Citations to foreign language articles & 14.0 & 1.8 \\
\hline
\end{tabular}

French materials, the highest concentration of French material in any discipline. Literature, more than all other fields except religion, was strongly dominated by monographs, with 83.0 percent of all citations referring to monographs. Literature was also more dominated than average by English language citations, with 83.8 percent of all citations referring to materials in English.

On the question of books versus journal articles, this study found a percentage of monographs similar to those found by Cullars, Stern, and Thompson. Although they were each studying different areas of literature, this congruence of findings argues for a consistency in the practice of literature scholars across the field. The one exception to this congruence was the study by Budd, who found a much lower 64 percent of citations to books and a higher 26.7 percent to serials; however, the fact that he

TABLE 12

Literature: LANguage Distribution

\begin{tabular}{lrc}
\hline \hline Language Distribution & Number & Percentage \\
\hline English & 650 & 83.8 \\
German & 2 & .3 \\
French & 91 & 11.7 \\
Italian & 2 & .3 \\
Spanish & 18 & 2.3 \\
Portuguese & 0 & 0 \\
Latin & 10 & 1.3 \\
Other languages & 0 & 0 \\
All foreign languages & 123 & 15.9 \\
\hline
\end{tabular}


counted manuscripts, unpublished letters, and dissertations separately would alter the percentages of books and journals found.

Cullars's was the only previous study that looked at the language of the citations, but, because his study was aimed specifically at scholars of foreign literatures, one would expect the much higher numbers of foreign language citations that he found. Literature is the most problematic field in which to do analysis of foreign language citations because the objects of its study are so closely tied to the languages in which they are written. This is illustrated by the observation made while counting citations in PMLA for the current study. The articles about writers such as Montaigne or genres such as the modern Cuban novel, for example, had a high concentration of foreign citations, while most topics in American or British literature had few or none (with the possible exception of the early modern period of British literature). While some writers on the humanities find this lack of awareness of foreign language works on the part of students and scholars of English literature lamentable, the fact remains that, for collection development librarians, the fields of study of the faculty (and by extension, the students) at their campuses will strongly influence what foreign language resources will be needed [36, p. 690]. Further research into the practices regarding language use in a broader array of the subspecialties of English literature would be useful to see if the trend seen here on a small scale holds true.

Music

In the field of music, two studies have looked at citations from dissertations and theses. The study by Kuyper-Rushing focused on identifying core journal titles for music libraries but also reported on the relative percentages of books and journals in several subfields of music [37]. In the area of musicology, selected for this study, Kuyper-Rushing studied 3,040 citations and found 36 percent were to books, 19 percent were to serials, and 44 percent were to other (which included music and other media). Language was not included. An earlier study by Griscom also focused on periodical use and found that in musicology, 63.8 percent of citations were to books, 23.6 percent were to journals, and 12.6 percent were to other sources [38] (see tables 13 and 14).

Articles in music were the longest, averaging 46.3 pages. This is nearly double the overall average of 24.2 pages. Probably as a result of these unusually long articles, music also had the fewest articles per volume with only nine. The long articles probably also account for the lower number of citations per page (1.5). The 67.6 citations per article, however, were 
TABLE 13

Music: Statistics

\begin{tabular}{lrc}
\hline \hline Statistic & Number & Percentage \\
\hline Total citations & 608.0 & $\ldots$ \\
Total pages 2002 volumes & 417.0 & $\ldots$ \\
Total articles 2002 volumes & 9.0 & $\ldots$ \\
Average pages per article & 46.3 & $\ldots$ \\
Average citations per article & 67.6 & $\ldots$ \\
Average citations per page & 1.5 & $\ldots$ \\
Total monographs cited & 490.0 & 80.6 \\
Total articles cited & 117.0 & 19.2 \\
Electronic sources & 1.0 & .2 \\
Citations to English monographs & 341.0 & 56.1 \\
Citations to English articles & 96.0 & 15.8 \\
Citations to foreign language monographs & 149.0 & 24.5 \\
Citations to foreign language articles & 21.0 & 3.5 \\
\hline
\end{tabular}

close to the average of 62.5. Music scholars cited high percentages of French (10.9 percent) and Italian (8.9 percent) sources; in each case, this represented the second highest percentage of citations to that language. Music also represented the highest use of Spanish materials, with 2.8 percent of citations referring to Spanish-language sources.

Citations to monographs in this field were strikingly different from earlier studies. While this study found 80.6 percent of citations were to monographs, earlier studies found a mere 36 percent (Kuyper-Rushing), and 63.8 percent (Griscom) [37, 38]. Kuyper-Rushing's study investigated citations in music dissertations only. It is possible that the different format may partly account for the disparate numbers, as well as the fact that music and other media were counted, thus lowering the overall percentages of

TABLE 14

Music: Language Distribution

\begin{tabular}{lcc}
\hline \hline Language Distribution & Number & Percentage \\
\hline English & 437 & 71.9 \\
German & 28 & 4.6 \\
French & 66 & 10.9 \\
Italian & 54 & 8.9 \\
Spanish & 17 & 2.8 \\
Portuguese & 0 & 0 \\
Latin & 5 & .8 \\
Other languages & 0 & 0 \\
All foreign languages & 170 & 28.0 \\
\hline
\end{tabular}


books and journals. Because of the differences in methods and the wide discrepancy of results between the current and previous studies, further research into the field of music is desirable.

Philosophy

The study by Ylva Lindholm-Romantschuk and Julian Warner includes philosophy as one of three fields studied. Because their goal was to examine the transmission of ideas, their methodology differs from the typical citation analysis [39]. They selected monographs from the outstanding books listed in Choice and then counted citations in Arts and Humanities Citation Index to those monographs and to articles by the same authors. They found a much higher percentage of monographs to journals cited, 88.5 percent to 11.4 percent (based on their raw number of citations) than did the present study. A more comparable study is that of Cullars (1998), who studied 539 randomly selected citations from monographs indexed by Philosophers' Index [40]. He also found a high percentage of monographic citations: 84.6 percent to books and articles in books, 13.4 percent to journal articles, and the remainder to manuscripts and theses. Cullars also reported on the language distribution of the citations, noting that 84.6 percent were to English sources or translations into English, 8.4 percent were to German, 2.6 percent were to Latin, 2 percent were to French, 2 percent were to Greek, and .4 percent were to other (one each to Italian and Spanish). Cullars's method differed from the present study in that he counted multiple references to the same work if they occurred in his sample, and he included references to the primary source books the authors were writing about (see tables 15 and 16).

Philosophy stood out with its unusually low percentage of citations to monographs, which represented only 51.4 percent of all citations. Philosophy was also unusually high in the number of citations to English-language sources with 99.7 percent of all citations referring to materials in English. Philosophy consistently had very low numbers of citations, with only 28.4 citations per article, less than half the overall average (62.5) and only a quarter as many as art (112.7). Although philosophy had more total citations than religion, religion had far fewer articles of the same length. When compared by citations per article and per page, philosophy was lower than any other field. Though these data seem strangely divergent from expectations and appear to be an anomaly, an earlier study of multiple volumes of the Journal of Philosophy found these numbers to be representative of citation patterns in the journal over several decades [9]. It is important to note that the subdiscipline of the history of philosophy would likely produce data more like that found in classics. However, this study 
TABLE 15

Philosophy: STAtistics

\begin{tabular}{lcc}
\hline \hline Statistic & Number & Percentage \\
\hline Total citations & 678.0 &. \\
Total pages 2002 volumes & 531.0 &. \\
Total articles 2002 volumes & 24.0 &. \\
Average pages per article & 22.1 &. \\
Average citations per article & 28.3 &. \\
Average citations per page & 1.3 &. \\
Total monographs cited & 350.0 & 51.4 \\
Total articles cited & 328.0 & 48.2 \\
Electronic sources & 3.0 & .4 \\
Citations to English monographs & 350.0 & 51.6 \\
Citations to English articles & 326.0 & 48.1 \\
Citations to foreign language monographs & 0 & 0 \\
Citations to foreign language articles & 2.0 & .3 \\
\hline
\end{tabular}

analyzes data from a journal that includes a variety of subfields of modern philosophy and is likely to be more representative of those areas.

In the field of philosophy, citation patterns that differed from earlier studies were found. Both the Lindholm-Romanstschuk study and the Cullars study found much higher percentages of citations to monographs [39, 40]. The Cullars study also found a lower percentage of citations to English. It is possible that these differences can be explained by the fact that both earlier studies investigated monographs, and the current study investigated journal articles. It is also likely that the earlier studies included more sources from narrow subfields of philosophy (e.g., historical philosophy), where foreign language and monographic materials are possibly more dominant. In addition, Cullars included source documents in his citation analysis; these were not included in the current study.

TABLE 16

Philosophy: Language Distribution

\begin{tabular}{lrc}
\hline \hline Language Distribution & Number & Percentage \\
\hline English & 676 & 99.7 \\
German & 1 & .1 \\
French & 1 & .1 \\
Italian & 0 & 0 \\
Spanish & 0 & 0 \\
Portuguese & 0 & 0 \\
Latin & 0 & 0 \\
Other languages & 0 & 0 \\
All foreign languages & 2 & .3 \\
\hline
\end{tabular}


Religion

Bowman, in his review article, reports on two studies of theology from the 1960s that reported 71.5 to 73.9 percent of citations were to books, and 23.2 to 24.8 percent to journals [4]. However, theology is a narrower field than religion, as reported in the present study, and Bowman included monographic series with journals in his table, making the numbers not strictly comparable (see tables 17 and 18).

In contrast with philosophy, religion is most extreme in its dominance of monographs, particularly in foreign languages. The citations to monographs in religion represented 88.2 percent of all citations; this is higher than the next highest field by 4.9 percent and higher than average by 13.9 percent. Only 0.9 percent of citations were to foreign language articles, further underscoring the dominance of monographs in religion. Religion had fewer total citations (450) than any other field, although the citations per article and per page were slightly higher than philosophy. While religion had a relatively low percentage of foreign citations compared with some of the other fields, it is interesting to note that German was the most cited foreign language in religion (more than twice as much as French, and Latin was cited almost as much as French). The wide variety of subfields in religion (from theology and biblical studies to Islam, Buddhism, etc.) makes this another field in which further research would be fruitful.

\section{Conclusion}

The details for each field noted in the "Results and Discussion" section above will be of interest to those responsible for collection development in those particular fields, but a few overall comparisons that seemed most striking are noted here. On the question of the relative numbers of citations to books versus those to journals, the fields of philosophy (51.4 percent books) and linguistics (60.8 percent books) show a higher than average reliance on journals. Conversely, literature (83.0 percent), music (80.6 percent), and religion (88.2 percent) showed a higher than average reliance on books. Thus, librarians might want to maintain journal subscriptions for philosophy and linguistics, at the expense of books, if necessary. At the same time, they might want to emphasize books for literature, music, and religion. The wide variance in use of foreign language sources by the different fields also has collection development implications. Of particular note is the relatively high use of these sources in art, classics, history, and music. Thus, continuing to purchase sources from foreign language vendors for these fields is important in order to meet the research needs of scholars. Even literature and religion had over 15 percent of citations to 
TABLE 17

ReLigion: STATISTICS

\begin{tabular}{lrc}
\hline \hline Statistic & Number & Percentage \\
\hline Total citations & 450.0 & $\ldots$ \\
Total pages 2002 volumes & 317.0 & $\ldots$ \\
Total articles 2002 volumes & 14.0 & $\ldots$ \\
Average pages per article & 22.6 & $\ldots$ \\
Average citations per article & 32.1 & $\ldots$ \\
Average citations per page & 1.4 &. \\
Total monographs cited & 397.0 &. \\
Total articles cited & 53.0 & 0 \\
Electronic sources & 0 & 71.8 \\
Citations to English monographs & 332.0 & 10.9 \\
Citations to English articles & 49.0 & 14.4 \\
Citations to foreign language monographs & 65.0 & .9 \\
Citations to foreign language articles & 4.0 & \\
\hline
\end{tabular}

foreign language sources, so they should not be ignored in purchasing decisions.

Of greatest interest is the wide variance in which languages are most important to each field (noted in fig. 2). While this result may be of no surprise to scholars in those fields, for collection development librarians this information may be useful, especially if they are responsible for fields outside their own academic preparation. The importance of a language in a field may be related to the research topics of most interest at any given time. For example, in the field of art there were a large number of articles on topics concerning the Renaissance in Italy, which would help to explain the high number of Italian citations in that field. The popularity of research topics in humanities fields changes over time, and the prevalence of topics in major journals may not correspond to the research

TABLE 18

Religion: LANGUAge Distribution

\begin{tabular}{lrc}
\hline \hline Language Distribution & Number & Percentage \\
\hline English & 381 & 84.7 \\
German & 39 & 8.7 \\
French & 15 & 3.3 \\
Italian & 1 & .2 \\
Spanish & 0 & 0 \\
Portuguese & 0 & 0 \\
Latin & 14 & 3.1 \\
Other languages & 0 & 0 \\
All foreign languages & 69 & 15.3 \\
\hline
\end{tabular}


interests of the faculty at a specific institution; therefore, caution should be used in generalizing these results to a particular library collection. It could prove useful for librarians to survey the specific research agendas of their local faculty and graduate students in order to supplement the broader analysis illustrated here. Meeting the needs of one's own faculty and students for research materials should, of course, have the highest priority. However, in weighing the long-term needs of the collection as a whole, the data presented in this article may provide some assistance to collection development librarians.

As was noted in the results sections on each field, in many cases the results of this study vary somewhat from those of previous studies. The suggested explanation of differences in methodology may or may not be valid. Further studies using a consistent methodology, but examining more journal titles and more years, would be useful in determining how accurate the percentages found in this study are. Precise percentages, however, are less important than the ability to make comparisons among humanities fields. We believe this study provides such comparisons. At times, striking differences were observed. They serve as a reminder that the humanities are not monolithic but, instead, are as varied as the human endeavors they study.

\section{REFERENCES}

1. Lascar, Claudia, and Mendelsohn, Loren D. "An Analysis of Journal Use by Structural Biologists with Applications for Journal Collection Development Decisions." College $\mathcal{E}^{\circ}$ Research Libraries 62, no. 5 (2001): 422-33.

2. Bollag, Burton. "The New Latin: English Dominates in Academe." Chronicle of Higher Education (September 8, 2000): A73.

3. Watson-Boone, Rebecca. "The Information Needs and Habits of Humanities Scholars." $R Q 34$ (1994): 213.

4. Bowman, Michael. "Format Citation Patterns and Their Implications for Collection Development in Research Libraries." Collection Building 11, no. 1 (1991-92): 2-8.

5. Devin, Robin B., and Kellogg, Martha. "The Serial/Monograph Ratio in Research Libraries: Budgeting in Light of Citation Studies." College Eं Research Libraries 51 (1990): 46-51.

6. Hutchins, W. J.; Pargeter, L. J.; and Saunders, W. L. "The Language Barrier: A Study in Depth of the Place of Foreign Language Materials in the Research Activity of an Academic Community." Unpublished manuscript. University of Sheffield, Postgraduate School of Librarianship and Information Science, 1971.

7. Herubel, Jean-Pierre V. M., and Buchanan, Anne L. "Citation Studies in the Humanities and Social Sciences: A Selective and Annotated Bibliography." Collection Management 18, nos. 3-4 (1994): 89-137.

8. Thompson, Jennifer Wolfe. "The Death of the Scholarly Monograph in the Humanities? Citation Patterns in Literary Scholarship." Libri 52 (2002): 121-36.

9. Kellsey, Charlene, and Knievel, Jennifer E. "Global English in the Humanities? A Lon- 
gitudinal Citation Study of Foreign Language Use by Humanities Scholars." College $\mathcal{E}$ Research Libraries 65, no. 3 (2004): 194-204.

10. De Luise, Alexandra A. "Journals of the Century in the Visual Arts." Serials Librarian 39, no. 4 (2001): 79-102.

11. Jenkins, Fred W. Classical Studies: A Guide to the Reference Literature. Reference Sources in the Humanities Series. Edited by James Rettig. Englewood, CO: Libraries Unlimited, 1996.

12. Lowe, M. Sara. "Reference Analysis of the American Historical Review." Collection Building 22, no. 1 (2003): 13-20.

13. Herubel, Jean-Pierre V. M., and Goedeken, Edward A. "Trends in Historical Scholarship as Evidenced in The American Historical Review: 1896-1990." Serials Review 19, no. 2 (1993): 79-83.

14. DeMiller, Anna L. Linguistics: A Guide to the Reference Literature. 2nd ed. Reference Sources in the Humanities Series. Edited by James Rettig. Englewood, CO: Libraries Unlimited, 2000.

15. Nederhof, A. J., and Zwaan, R. A. "Quality Judgments of Journals as Indicators of Research Performance in the Humanities and the Social and Behavioral Sciences." Journal of the American Society for Information Science 42, no. 5 (1991): 332-40.

16. Karass, Alan. "Journals of the Century in Music." Serials Librarian 39, no. 3 (2001): 103-32.

17. Brockman, William S. Music: A Guide to the Reference Literature. Reference Sources in the Humanities Series. Edited by James Rettig. Littleton, CO: Libraries Unlimited, 1987.

18. Bynagle, Hans E. Philosophy: A Guide to the Reference Literature. 2nd ed. Reference Sources in the Humanities Series. Edited by James Rettig. Englewood, CO: Libraries Unlimited, 1997.

19. Cullars, John. "Journals of the Century in Philosophy." Serials Librarian 39, no. 2 (2000): 39-58.

20. Gilton, Donna. "Journals of the Century in the American Religious Experience." Serials Librarian 39, no. 4 (2001): 25-39.

21. Fieg, Eugene C., Jr., compiler. Religion Journals and Serials: An Analytical Guide. Annotated Bibliographies of Serials: A Subject Approach, vol. 13. Edited by Norman Frankel. New York: Greenwood, 1988.

22. Dawsey, James. A Scholar's Guide to Academic Journals in Religion. ALTA Bibliography Series, vol. 23. Edited by Kenneth E. Rowe. Metuchen, NJ: Scarecrow, 1988.

23. Herring, Susan Davis. "Use of Electronic Resources in Scholarly Electronic Journals: A Citation Analysis." College $\mathcal{E}$ Research Libraries 63, no. 4 (2002): 334-40.

24. Barkett, Gina R. "Case Study 4.3: Conducting a Citation Analysis." In Library Evaluation: A Casebook and Can-Do Guide, edited by Danny P. Wallace and Connie Van Fleet, pp. 155-64. Englewood, CO: Libraries Unlimited, 2001.

25. Cullars, John. "Citation Characteristics of Monographs in the Fine Arts." Library Quarterly 62 (1992): 325-42.

26. Simonton, Wesley Clark. "Characteristics of the Research Literature of the Fine Arts during the Period 1948-1957." PhD diss., University of Illinois at Urbana Champaign, 1960.

27. Cullars, John. "Citation Characteristics of French and German Fine Arts Monographs." Library Quarterly 66 (1996): 138-60.

28. Dowell, Erika. "Interdisciplinarity and New Methodologies in Art History: A Citation Analysis." Art Documentation 18, no. 1 (1999): 14-19.

29. Nelson, Diane M. "Methods of Citation Analysis in the Fine Arts." Special Libraries 68 (1977): 390-95.

30. Tucker, Benny Ray. "Characteristics of the Literature Cited by Authors of the Transactions of the American Philological Association, 1956 and 1957." Master's thesis, University of North Carolina, 1959. 
31. Jones, Clyve; Chapman, Michael; and Woods, Pamela Carr. "The Characteristics of the Literature Used by Historians." Journal of Librarianship 4, no. 3 (1972): 137-56.

32. Herubel, Jean-Pierre V. M. "The Nature of Three History Journals: A Citation Experiment." Collection Management 12, nos. $3 / 4$ (1990): 57-67.

33. Cullars, John. "Characteristics of the Monographic Scholarship of Foreign Literary Studies by Native Speakers of English.” College E Research Libraries 49 (1988): 157-70.

34. Budd, John. "A Citation Study of American Literature: Implications for Collection Management." Collection Management 8, no. 2 (1986): 49-62.

35. Stern, Madeline. "Characteristics of the Literature of Literary Scholarship." College $\mathcal{E}$ Research Libraries 44 (1983): 199-209.

36. Patty, Gabrielle M. "Foreign-Language Study for Graduate English Majors." College English 51, no. 7 (1989): 688-700.

37. Kuyper-Rushing, Lois. "Identifying Uniform Core Journal Titles for Music Libraries: A Dissertation Citation Study." College E Research Libraries 60, no. 2 (1999): 153-63.

38. Griscom, Richard. "Periodical Use in a University Music Library: A Citation Study of Theses and Dissertations Submitted to the Indiana University School of Music from 1975-1980." Serials Librarian 7, no. 3 (1983): 35-47.

39. Lindholm-Romantschuk, Ylva, and Warner, Julian. "The Role of Monographs in Scholarly Communication: An Empirical Study of Philosophy, Sociology and Economics." Journal of Documentation 52, no. 4 (1996): 389-404.

40. Cullars, John. "Citation Characteristics of English Language Monographs in Philosophy." Library and Information Science Research 20, no. 1 (1998): 41-68. 